\title{
Effect of Visual Feedback Squat Motion on Core Muscles Thickness of Young People with Lower Back Pain
}

\author{
HoJin Jeong', ChiBock Park², YongNam Kim³ \\ 'Department of Physical Therapy, Graduate School, Nambu University, Gwangju; ${ }^{2}$ Department of Physical Therapy, Somoonnan Orthopedic Clinic, \\ Gwangju; ${ }^{3}$ Department of Physical Therapy, Nambu University, Gwangju, Korea
}

Purpose: This study examined the effect of visual feedback squat on the core muscle thickness of young adults experiencing back pain. Methods: Thirty adult men and women who experienced back pain were assigned randomly to 15 members of the visual feedback squat group (VSG) and 15 of the normal squat group (NSG) to train three times a week for a total of eight weeks. The core muscle thickness was compared prior to the test for four weeks and eight weeks after the test by dividing it into warm-up exercise, main exercise, and 10 minutes finishing exercise. Before, and four weeks and eight weeks later, the thickness of the core muscle was compared using an ultrasonic imaging system.

Repeated measured ANOVA was performed to compare the groups, and a Bonferroni test was performed as a post-hoc test to assess the significance of the timing of the measurements in each group according to the periods. An independent t-test was conducted to test the significance between the groups according to the measurement points.

Results: A significant change in the main effects of time and interactions of the time difference in muscle thickness of transvers abdominis were observed between the visual feedback squat and control groups according to the measurement point $(p<0.05)$. No significant difference in the muscle thickness of both muscles was observed between the groups with the exception of the right abdominis $(p>0.05)$.

Conclusion: These findings suggest that visual feedback squat exercise is expected to have positive effects on the development of transverse abdominis in core muscles.

Keywords: Squat exercise, Core muscle, Visual feedback, Lower back pain.

\section{서 론}

요통은 어떠한 연령층에도 발생할 수 있으며 최근에는 인터넷의 발 달로 인해 앉아서 활동하는 시간의 증가, 생활습관의 변화 및 진단 방법의 발달로 20-30대의 젊은 층의 환자가 증가하고 있다. ${ }^{1}$ 요통은 근골격계의 이상으로 인한 통증을 말하며 등뼈 10 번 이하의 허리부 위에 통증이 3 일 이상 지속되는 경우를 말한다. ${ }^{2}$

근골격계 질환에서 가장 대표적인 요통질환은 직립자세로 활동 을 하는 인간의 척추가 만곡이 형성되어 있기 때문에 척추주변을 지 지하는 근육과 인대의 기능을 약화시키는 잘못된 자세, 허리의 과도 한 움직임은 요통을 유발시킬 수 있다. 현대 산업화 시대에 들어서면 서 몸을 사용하기 보다는 사무적인 업무로 인해 앉아서 실행하는 직 업이 늘어났다. 앉아있는 자세에서 불균형한 자세를 하고 신체를 움

Received Jul 1, 2019 Revised Aug 22, 2019

Accepted Aug 23, 2019

Corresponding author YongNam Kim

E-mail kyn5441@hanmail.net
직이는데 활동이 줄어들면서 관절의 강력한 스트레스와 근육퇴화로 인하여 요통에 영향을 준다고 보고하였다. ${ }^{4}$

요통의 관리는 장시간의 기간을 두고 예방과 재발방지의 다면적 해결방법으로 접근해야 하는데 코어운동은 통증완화와 근력강화에 효과적이고 일상생활 활동 수준 향상에 많은 도움이 되고 있다. ${ }^{5}$ 코 어운동 목적은 근골격계 질환의 치료와 신체조성 향상에 있다. 근육 의 약화나 불균형 시 요통을 유발 할 수 있다고 하였다. ${ }^{6}$ 이러한 통증 은 몸통 안정화 운동을 통해 요통이 완화 될 수 있다고 보고 되었다. ${ }^{78}$ 허리안정화 운동은 환자 또는 정상인이 일상생활 또는 최적의 활동 을 수행하는 동안 척추에 가해지는 스트레스를 최대한 줄여주고, 신 경과 근육의 적절한 조절과 협응력 유지 및 허리 골반 부위의 안정화 에 관여 하는 근육, 배근육 등을 강화시키고, 반대로 단축된 근육의 경우 신장을 유발시키는 운동방법이다.' 이와 관련된 닫힌 사슬 운동 
스쿼트는 물리치료와 다양한 스포츠 환경에서 훈련프로그램 중 하 나이다. ${ }^{10}$ 스쿼트는 다리를 어깨 넓이만큼 양 옆으로 벌리고 서서 발 바닥을 땅에 지지하고 등을 펴고 무릎관절과 엉덩관절, 발목관절을 사용하여 앉았다가 일어나는 하지 저항운동이다. ${ }^{11}$ 스쿼트 운동은 달리기나 점프와 같은 동작에 있어 중요한 근육인 대퇴와 몸통 근육 을 단련시키며, 하체 훈련의 가장 기본이 되는 운동으로써 ${ }^{12,13}$ 다리 근육은 팔 근육에 비해 큰 근육이 많으며 체중지지, 충격흡수 등 상 체로 전달되는 중력에 대한 저항을 줄여주는 역할을 한다. 닫힌 사슬 운동인 스쿼트 운동은 넙다리, 종아리 근육 뿐 만 아니라, 몸통근육 의 배곧은근, 배바깥빗근, 배속빗근, 배가로근까지 동시에 발달시킬 수 있는 가장 적절한 운동이다. ${ }^{14}$

몸통근육들 중에서 배가로근과 뭇갈래근은 척추 안정화에 가장 크게 기여하여 근육의 약화나불균형 시 요통을 유발할수 있다고 하 였다.5 코어근육은 인체의 허리뼈와 골반, 배를 둘러싸고 있는 근육 을 말하며 팔과 다리의 움직임에 있어 근본적인 안정성을 제공해주 며, 외부 저항으로부터 몸의 안정성을 유지해주고 척추신경을 보호 하는 역할을 한다. ${ }^{15}$ 요통환자에서 몸통 안정화를 위한 코어 근육의 강화 운동이 허리 근육의 활성 비율에 영향을 미쳐 허리 및 골반의 안정화를 위해 매우 효과적이라는 결과도 보고된 바 있다..$^{16}$ 코어근육 의 배가로근, 배속빗근, 배바깥빗근의 역할 중 하나인 몸통의 안정성 은 척추의 손상을 예방하고 허리통증 환자의 재활을 위한 중요변수 로 여겨지고 있고, ${ }^{17}$ 코어근육의 동시수축은 허리뼈에 코르셋과 같은 보조기 역할을 하고, 척추의 위치와 무관하게 척추중립위치를 유지 하며 기능적인 운동을 하는 동안 척추분절의 안정성을 제공한다. ${ }^{18}$ 사지말단의 근육이 척추의 대한 지나친 스트레스 없이 동적 기능 활 동을 완수할 수 있도록 작용하는 코어근육들은 다양한 원인으로 약 화된 코어부위를 안정화하고 강화시켜 몸통과 허리뼈에 동적 안정화 및 신경근 운동조절 증진, 중력에 대한 수직 정렬을 조절한다. ${ }^{19}$

시각적 피드백 훈련은 평형감각과 몸감각으로부터 들어온 구심성 정보와 통합을 이루어 자세조절에 기여하고, 자세동요를 감소시킨다 고 하였고, ${ }^{20}$ 불수의적으로 발생하는 신체의 움직임을 수의적으로 조 절하는 자가 조절 기술이라고 할 수 있으며, 하지에서의 체중 분배와 압력 중심에 관한 정보를 제공하여, 균형을 훈련시키는데 도움을 준 다. ${ }^{21}$ 시각적 피드백 훈련은 운동과제를 수행하면서 끊임없는 자율적 수정을 반복하며 운동 계획과 운동 조절 능력이 계속해서 자극이 되 고, 신경 가소성에도 이점이 있다고 하였다.22,23

지금까지의 선행논문에서는 스쿼트 운동의 영향을 미치는 근육 중 하지위주의 근육을 중심으로 연구하였으며, 코어근육의 근두께 의 차이에 대한 연구는 아직까지 미흡한 실정이다. 따라서, 본 연구는 요통을 경험한 젊은 성인남녀의 시각적 피드백을 이용해 스쿼트 운 동이 코어근육의 근 두께에 어떠한 영향을 미치는지 규명하고 활성
화시킬 수 있는 치료개발에 기초자료로서 제공하는데 그 목적이 있다.

\section{연구방법}

\section{1. 연구대상}

본 연구는 $\mathrm{G}$ 시에 소재한 N대학의 20대 성인 남녀 중 요통을 경험한 성인 중 실험에 대한 설명 후 실험참여에 동의한 30 명을 실험군 15 명, 대조군 15 명으로 무작위 배치하였다. 참가자 30 명은 8주간 실험을 종 료하였다. 대상자 선정은 최근 6 개월 간 요부통증을 경험하거나 진단 을 받은 자, 최근 6개월 간 무릎통증, 발목통증을 경험하지 않았거나 진단받지 않은 자, 최근 6 개월 간 요통을 제외한 근골격계에 관련된 질병으로 약물복용 및 치료를 받지 않은 자 그리고 연구자의 설명을 이해하고 본 연구의 동의서에 자발적으로 동의한 자로 선정하였다.

\section{2. 실험방법}

모든 대상자들의 훈련프로그램은 주 3 회, 총 8 주 동안 실시하였다. 중재 방법은 운동 전 10 분 간의 준비 운동, 본 운동, 10 분 간의 마무리 운동으 로 나누어 실시하였다. 1-4주는 15개씩 5 sets 실시하였으며, 운동 강도 증진을 위해 5-8주는 20개씩 5 sets 실시하였다. 본 실험을 위한 운동 시 근육 손상을 줄이기 위해 $1 \mathrm{set}$ 당 3 분간의 휴식시간을 부여하였다.

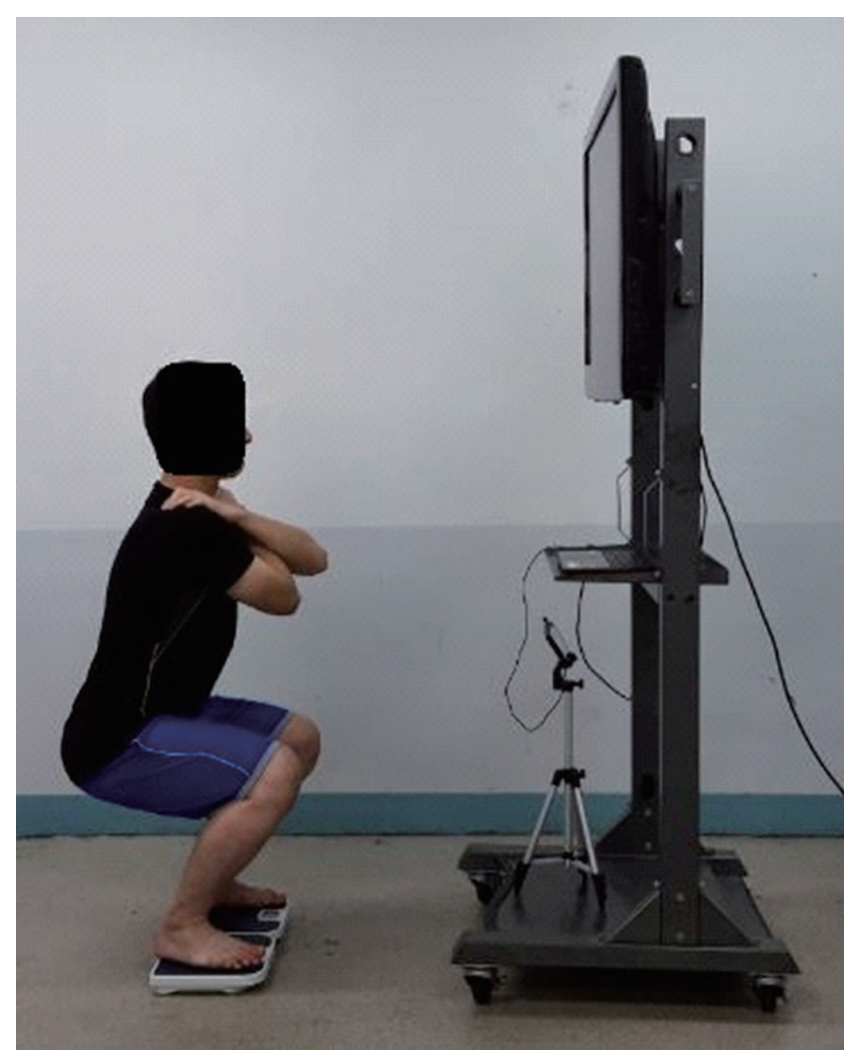

Figure 1. Visual feedback squat exercise. figure 
1) 실험군

실험군의 대상자에게는 체중계 2 개당 1 개의 삼각대를 이용하여 노 트북을 통해 모니터에 스마트폰 화면이 나올 수 있도록 Side Sync 어 플을 이용하여 연동시켜 시각적 피드백 스쿼트 운동을 시켰다. 허리 가 굽혀지지 않은 상태에서 양 발을 $45^{\circ}$ 각도로 벌리고 $90^{\circ}$ 각도의 무 릎관절 굽힘 된 스쿼트 운동을 실시하였으며, 주의할 점은 시선을 모 니터 화면으로 향하게 하여 실시간 연동되는 체중계를 보면서 양측의 체중 분포 변화 볼수 있도록 했다. 운동장비로는 SideSync 프로그램이 설치된 노트북(NT270E5j-k34m, Samsung, Korea), Side Sync 어플(Samsung, Korea)이 설치된 스마트폰(Galaxy Note 8, Samsung, Korea), 삼각 대(ET3110, China), 체중계 2대, 모니터(LG-27MT58DF, LG, Korea)를 이 용하여 시각적 피드백 장치로 사용하기 위해 연동하였다(Figure 1).

\section{2) 대조군}

대조군은 시각적 피드백이 없는 일반적인 스쿼트 운동을 실시하였다.

\section{3) 측정도구}

(1) 신체조성분석

체중, 체질량지수(body mass index, BMI)등을 알아내기 위해 체성분측정 기(Inbody 430, Biospace, Korea)를 통하여 신체조성 검사를 실시하였다.

간단한 복장으로 최대한 신체를 가볍게 한 후, 귀금속 등을 제거한 상태에서 체성분측정기 위에 올라간다. 측정기의 발판위에 발뒤꿈치 를 위치시킨 후 편안한 자세로 정면을 바라보며 선다. 양손 전극을 잡 은 뒤, 몸과 팔의 간격을 약 $15-20^{\circ}$ 정도 벌린 후 검사자의 지시에 따라 행동한다. 검사 종료 알림이 나오기 전까지 움직이지 않고 검사자는 장비로부터 최대한 멀리 떨어진다. ${ }^{24}$

\section{(2) 초음파(ultrasonic wave)}

코어근육과 몸통의 근 두께를 측정하기 위해 초음파영상장치(Achievo CST, V2u Health Care, Singapore)를 이용하여 테이블에 바로 누운 후 측정하였고, 모든 측정은 장비 사용에 능숙한 측정자가 사전과 중 간, 사후에 측정하였다. 측정방법으로 코어근육인 배가로근, 배속빗 근, 배바깥빗근은 겨드랑이 선에서 가쪽을 따라 아래 방향으로 그은 선과 배꼽이 만나는 점에서 앞쪽 $2.5 \mathrm{~cm}$ 부분을 측정하였다. 이 때 피 부의 압박을 최소화하기 위해 충분한 양의 초음파 겔을 사용하고 측 정이 일정하게 되도록 변환기와 피부를 직각으로 유지하였으며, 모든 측정은 3 회 측정하여 평균값으로 도출하였으며, 측정 사이 휴식시간 은 1 분으로 동일한 측정자가 사전과 같은 방법으로 진행하였다. ${ }^{25}$

\section{4) 분석방법}

본 연구의 자료처리 방법은 SPSS 22.0 통계 프로그램을 이용하여 측
정 항목에 대한 평균과 표준편차를 산출하여 도표화하였다. 대상자 의 일반적특성에 대한 동질성 검정은 독립표본 $\mathrm{t}$-검정을 사용하였다. 실험 전, 4 주 후, 8 주 후 각 집단 간 코어근육의 근 활성도를 비교하기 위하여 반복측정분산분석(repeated measured ANOVA)을 사용하였 고, 각 집단 내 측정 시기에 따른 유의성 검정을 위해 사후분석으로 bonferroni를 실시하였다. 각 측정시기 별 집단 간의 훈련효과 검정을 위해 독립표본 $\mathrm{t}$-검정을 사용하였다. 모든 변인에 대한 통계학적 유의 수준은 $\alpha=0.05$ 로 설정하였다.

\section{결 과}

\section{1. 연구대상자들의 일반적인 특성}

연구대상자는 20 대 성인 남녀를 대상으로 실험에 대한 설명 후 실험 참여에 동의한 성인을 대상으로 총 30 명이며, 실험군과 대조군 모두 15 명으로 배치하였다. 연구대상자의 일반적인 특성은 Table 1과 같다.

\section{2. 스쿼트 운동 후 오른쪽 근 두께의 변화}

시각적 피드백 스쿼트를 적용한 실험군과 일반 스쿼트를 적용한 대 조군의 오른쪽 근 두께의 변화에 대한 반복측정분산분석 결과 배바 깥빗근, 배속빗근은 시기의 주효과와 집단 간 시기의 상호작용이 유 의한 차이가 없었지만 $(\mathrm{p}>0.05)$, 배가로근은 시기의 주효과와 집단 간 시기의 상호작용이 유의한 차이가 있었다 $(\mathrm{p}<0.05)$.

배가로근의 각 군 내 측정시기에 따른 사후분석 결과 실험군은 0 주에서 8 주 후 $(\mathrm{p}<0.05)$, 대조군은 0 주에서 4 주 후에서 유의한 차이가 있었다 $(\mathrm{p}<0.05)$.

배바깥빗근의 각 군 내 측정시기에 따른 사후분석 결과 실험군에 서 0 주에서 8 주 후에서 유의한 차이가 있었다 $(\mathrm{p}<0.05)$.

각 측정 시기 별에 따른 집단 간의 비교에서 배가로근이 4 주, 8 주에 서 유의한 차이가 있었다 $(\mathrm{p}<0.05)$ (Table 2).

\section{3. 스쿼트 운동 후 왼쪽 근 두께의 변화}

시각적 피드백 스쿼트를 적용한 실험군과 일반 스쿼트를 적용한 대 조군의 왼쪽 근 두께의 변화를 알아본 결과 배바깥빗근, 배속빗근은

Table 1. General characteristics of the subjects

\begin{tabular}{lccc}
\hline & VSG $(n=15)$ & NSG $(n=15)$ & $p$ \\
\hline Gender (male / female) & $7 / 8$ & $7 / 8$ & \\
Age (years) & $21.20 \pm 1.82^{\mathrm{a}}$ & $21.13 \pm 1.77$ & 0.563 \\
Weight $(\mathrm{kg})$ & $65.17 \pm 14.01$ & $70.09 \pm 10.60$ & 0.355 \\
Height $(\mathrm{cm})$ & $167.87 \pm 10.59$ & $167.33 \pm 7.62$ & 0.137 \\
BMl $\left(\mathrm{kg} / \mathrm{m}^{2}\right)$ & $22.86 \pm 2.50$ & $25.11 \pm 4.08$ & 0.063 \\
\hline
\end{tabular}

aMean \pm SD, VSG: visual feedback squat group, NSG: normal squat group, BMl: body mass index.. 
Table 2. Comparison of the results of right muscles thickness after squat exercise

\begin{tabular}{|c|c|c|c|c|c|c|c|}
\hline & Group & Pre & Mid & Post & Source & $\mathrm{F}$ & $p$ \\
\hline \multirow[t]{5}{*}{ External Oblique } & VSG $(n=15)$ & $0.42 \pm 0.056$ & $0.45 \pm 0.083$ & $0.52 \pm 0.158^{b}$ & Group & 2.281 & 0.142 \\
\hline & & & & & Time & 6.609 & $0.005^{*}$ \\
\hline & NSG $(n=15)$ & $0.40 \pm 0.066$ & $0.42 \pm 0.056$ & $0.44 \pm 0.104$ & $G * T$ & 1.012 & 0.377 \\
\hline & $\mathrm{t}$ & 0.861 & 1.321 & 1.573 & & & \\
\hline & $\mathrm{p}$ & 0.397 & 0.199 & 0.129 & & & \\
\hline \multirow[t]{5}{*}{ Internal Oblique } & VSG $(n=15)$ & $0.92 \pm 0.201$ & $0.93 \pm 0.185$ & $1.00 \pm 0.308$ & Group & 0.631 & 0.434 \\
\hline & & & & & Time & 4.337 & $0.021^{*}$ \\
\hline & NSG $(n=15)$ & $0.86 \pm 0.199$ & $0.87 \pm 0.196$ & $0.95 \pm 0.284$ & $G * T$ & 0.015 & 0.979 \\
\hline & $\mathrm{t}$ & 0.867 & 0.939 & 0.507 & & & \\
\hline & $\mathrm{p}$ & 0.393 & 0.356 & 0.616 & & & \\
\hline \multirow[t]{5}{*}{ Transverse Abdominis } & VSG $(n=15)$ & $0.37 \pm 0.054$ & $0.39 \pm 0.048$ & $0.47 \pm 0.094^{b}$ & Group & 4.128 & 0.052 \\
\hline & & & & & Time & 29.177 & $0.000^{*}$ \\
\hline & NSG $(n=15)$ & $0.38 \pm 0.045$ & $0.34 \pm 0.035^{a}$ & $0.39 \pm 0.049$ & $G * T$ & 13.715 & $0.000^{*}$ \\
\hline & $\mathrm{t}$ & -0.917 & 3.544 & 2.66 & & & \\
\hline & $\mathrm{p}$ & 0.367 & $0.001^{*}$ & $0.013^{*}$ & & & \\
\hline
\end{tabular}

All values are shown in mean \pm standard deviation, ${ }^{*} p<0.05$, ${ }^{a}$ post-hoc (pre-mid) $p<0.05,{ }^{b}$ post-hoc (pre-post) $p<0.05$, VSG: visual feedback squat group, NSG: normal squat group.

Table 3. Comparison of the results of left muscles thickness after squat exercise

\begin{tabular}{|c|c|c|c|c|c|c|c|}
\hline & Group & Pre & Mid & Post & Source & $\mathrm{F}$ & $p$ \\
\hline \multirow[t]{5}{*}{ External Oblique } & VSG $(n=15)$ & $0.42 \pm 0.075$ & $0.46 \pm 0.111$ & $0.52 \pm 0.182$ & Group & 1.110 & 0.301 \\
\hline & & & & & Time & 6.538 & $0.005^{*}$ \\
\hline & NSG $(n=15)$ & $0.42 \pm 0.077$ & $0.41 \pm 0.053$ & $0.46 \pm 0.093$ & $G * T$ & 1.075 & 0.356 \\
\hline & $\mathrm{t}$ & 0.248 & 1.439 & 1.009 & & & \\
\hline & $\mathrm{p}$ & 0.806 & 0.166 & 0.325 & & & \\
\hline \multirow[t]{5}{*}{ Internal Oblique } & VSG $(n=15)$ & $0.93 \pm 0.219$ & $1.00 \pm 0.288$ & $1.09 \pm 0.842$ & Group & 1.497 & 0.231 \\
\hline & & & & & Time & 2.1 & 0.142 \\
\hline & NSG $(n=15)$ & $0.82 \pm 0.190$ & $0.85 \pm 0.172$ & $0.93 \pm 0.214$ & $G * T$ & 0.451 & 0.642 \\
\hline & $\mathrm{t}$ & 1.342 & 1.716 & 0.724 & & & \\
\hline & $\mathrm{p}$ & 0.190 & 0.100 & 0.475 & & & \\
\hline \multirow[t]{5}{*}{ Transverse Abdominis } & VSG $(n=15)$ & $0.34 \pm 0.051$ & $0.38 \pm 0.040^{a}$ & $0.42 \pm 0.045^{b}$ & Group & 0.852 & 0.364 \\
\hline & & & & & Time & 73.719 & $0.000^{*}$ \\
\hline & NSG $(n=15)$ & $0.33 \pm 0.036$ & $0.37 \pm 0.044^{a}$ & $0.39 \pm 0.040^{b}$ & $G * T$ & 2.134 & 0.138 \\
\hline & $\mathrm{t}$ & 0.595 & 0.434 & 1.439 & & & \\
\hline & $\mathrm{p}$ & 0.557 & 0.667 & 0.161 & & & \\
\hline
\end{tabular}

All values are shown in mean \pm standard deviation, ${ }^{*} p<0.05$, apost-hoc (pre-mid) $p<0.05,{ }^{b}$ post-hoc (pre-post) $p<0.05$, VSG: visual feedback squat group, NSG: normal squat group.

시기의 주효과와 집단 간 시기의 상호작용이 유의한 차이가 없었지 만(p>0.05), 배가로근은 시기의 주효과에는 유의한 차이가 있었지만 $(\mathrm{p}<0.05)$, 집단 간 시기의 상호작용이 유의한 차이가 없었다 $(\mathrm{p}>0.05)$.

배가로근의 각 군 내 측정시기에 따른 사후분석 결과 실험군은 0 주에서 4 주 후 $(\mathrm{p}<0.05), 0$ 주에서 8 주 후 $(\mathrm{p}<0.05)$, 대조군은 0 주에서 4 주 후 $(\mathrm{p}<0.05), 0$ 주에서 8 주 후 에서 유의한 차이가 있었다 $(\mathrm{p}<0.05)$.

각 측정 시기 별에 따른 집단 간의 비교에서 모두 유의한차이가 나 타나지 않았다( $\mathrm{p}>0.05)($ Table 3).

\section{고 찰}

본 연구의 목적은 요통을 경험한 대상자가 시각적 피드백 스쿼트 운 동과 일반적 스쿼트 운동을 8 주간 수행하였을 때 각 시기별, 그룹 간 에 양쪽 배속빗근, 배바깥빗근, 배가로근의 근두께의 변화를 비교하 여, 시각적 피드백 스쿼트 운동의 효과를 확인하는 것이 목적이었다. 본 연구에서는 시각적 피드백 스쿼트 운동군과 일반 스쿼트 운동 군으로 나누어 연구해 본 결과 오른쪽 배속빗근, 왼쪽 배속빗근, 오른 쪽 배바깥빗근, 왼쪽 배바깥빗근, 왼쪽 배가로근에서는 유의한 차이 
가 나타나지 않았으나, 오른쪽 배가로근은 4 주차 8 주차에서 유의한 차이가 있었다.

이소희 26 는 20 세 초반 만성 요통 환자를 대상으로 배근육을 수축 시켰을 때 능동적 다리 곧게 들어올리기 또는 능동적 발등 굽힘을 병 행할 시 능동적 다리 곧게 들어올리기는 수축 시 배바깥빗근, 배속빗 근, 배가로근이 증가하였고, 능동적 발등 굽힘은 휴식 시 배속빗근과 수축 시 배속빗근과 배가로근이 증가하였다고 보고 하여 본 연구의 결과와 대조되었다.

선행연구에서는 유의한 차이가 나타났지만 본 연구에서는 기간이 짧고, 대상자가 환자가 아닌 단순 요통을 경험한 젊은 성인 남녀를 대 상으로 연구하였기 때문에 변화가 없는 것이라 사료된다.

도용찬근 여러 가지의 지면 플랭크 운동을 실시하였을 때 휴식 상태의 이완된 배가로근과 배속빗근 두께를 기준으로 3 가지 지면 유 형별 플랭크 운동 모두 배가로근과 배속빗근의 두께가 유의하게 증 가하였다.

본 연구에서는 배속빗근의 두께는 유의하지 않았고, 왼쪽 배가로 근에서는 시기의 주효과에서 유의한 차이가 있었으며, 오른쪽 배가 로근에서는 시기의 주효과와 그룹간 시기의 상호작용에 유의한 차이 가 있는 것으로 나타났다.

선행논문에서는 배가로근과 배속빗근이 유의한 차이가 나타났지 만 본 연구에서는 시각적 피드백 스쿼트 운동군의 오른쪽 배가로근 의 두께에서 유의하게 증가하였으며 왼쪽 배가로근에서는 두 그룹 모두 유의하게 증가하였다는 점에서 하지의 불안정성을 극복하고 골 반의 안정성을 확보하기 위해 배가로근이 상대적으로 크게 작용하기 때문에 그 두께 변화량이 유의하게 큰 것으로 사료된다. 이는 두 그룹 에 시행된 운동 모두 비우세측의 근육을 증가시킬 수 있는 요인이 되 며 우세측에서는 시각적 피드백 스쿼트 운동이 균형있게 증가시킬 수 있는 좋은 방법이라고 사료된다.

이태경 28 은 만성 요통환자 그룹과 건강한 성인 그룹을 대상으로 코 어 근지구력 테스트인 prone bridge와 supine bridge test를 실시하였을 때 prone bridge 시 배속빗근, 배바깥빗근이 유의하게 차이를 보였고, supine bridge 시 배바깥빗근에서 유의하게 차이가 난 것으로 보고 하 여 본 연구의 결과와 대조되었다.

또한 만성요통환자의 몸통근지구력 검사 시 심부배근육 두께 변 화에 대한 선행연구에서는 만성요통환자의 배속빗근과 배바깥빗근 이 유의한 차이가 나타났지만 본 연구에서는 실험군과 대조군의 구 분을 만성요통 환자와 건강한 성인을 대상으로 하지 않았으며, 측정 시기 또한 1 일 1 번 측정하지 않았기에 유의한 차이가 나타나지 않았 다고 사료된다.

문달주29는 몸통안정화 운동을 실시하였을 때 배가로근, 배속빗근, 배바깥빗근이 유의한 차이가 나타났으며 서 있는 자세에서 균형적
운동은 동시적으로 균형조절능력을 동요시키며 코어근육의 근활성 도에 영향을 준다고 보고하였다. 또한 남동형 30 은 20 대 대학생에게 시 각적 피드백을 이용한 스쿼트 운동을 적용한 결과 배가로근의 근두 께에 유의한 증가가 있었다고 보고하였으며, 시각적 피드백을 적용한 군과 적용하지 않은 군의 각 군 모두 실험 전후에 모두 유의한 차이가 있었지만 실험 후에 대한 비교결과 시각적 피드백 적용군이 비적용 군보다 유의한 증가가 있었으며 이는 시각적으로 보여지는 수치가 양 하지의 균형능력과 고유수용성 감각을 자극시켜 더욱 효과적인 운 동 방법이라고 제언하였다.

본 연구에서는 양쪽 배속빗근, 배바깥빗근의 근 두께는 군간 비교 와 시기별 차이에 유의한 차이가 나타나지 않았지만, 시각적 피드백 스쿼트 운동 군의 오른쪽 배가로근의 두께의 0 주에서 8 주사이의 시 기 별 유의하게 증가하고 각 그룹의 왼쪽 배가로근의 두께가 0 주에서 4 주, 0 주에서 8 주 모두 시기별로 유의하게 증가하였다는 점에서 시각 적 피드백을 적용한 운동이 신체의 균형능력과 고유수용성 감각을 자극시켜 배가로근의 근두께에 긍정적인 영향을 미쳤다고 사료된다. 반면 배속빗근과 배바깥빗근에 대해서는 본 연구는 대상자를 요통 환자들로 선정하였고, 선행논문에서는 병이 없는 건강한 성인 남녀 를 대상으로 했다는 점에 반해 본 연구에서는 요통을 경험한 자를 대 상으로 한 점에서 차이가 있을 것으로 사료된다.

또한 하지의 굽힘 운동을 통해 시행되는 스쿼트 운동이 배속빗근 과 배바깥빗근의 근두께 변화에 미치는 영향이 보다 미비하다고 사 료되며, 우세측 근육이 시각적 피드백 스쿼트 운동을 하였을 때 일반 적 스쿼트 운동에 비해 근두께의 증가에 영향을 줄 수 있다고 사료된 다. 추가적으로 비우세측에서는 시각적 피드백 장치의 유무에 관계 없이 스쿼트 운동을 시행 함으로써 좀 더 배가로근의 근두께에 긍정 적인 영향을 줄수 있다고 사료된다.

본 연구에서는 몇 가지 제한점을 가지고 있다. 첫째, 본 연구의 대상 자는 20 대 요통을 경험한 자로만 한정적으로 진행하였다. 향후 연구 에서는 다양한 연령층의 대상으로 연구를 진행한다면 본 연구와 다 른 결과를 얻을 수 있을 것이다. 둘째, 본 연구는 배근육인 배가로근, 배속빗근, 배바깥빗근 만을 검사하였다. 향후 연구에서는 배근육 뿐 아니라 볼기근, 넙다리두갈래근 등 다양한 근육의 수축이나 활성도 를 검사한다면 보다 정확하고 다양한 결과를 얻을 수 있을 것이다. 셋 째, 본 연구는 코어근육의 근 두께를 보다 정밀히 비교하기에는 다소 기간이 짧았다. 따라서 향후에는 보다 오랜 기간을 적용하여 정확한 시각적 피드백 운동이 될 수 있는 연구가 필요할 것이다.

\section{REFERENCES}

1. Lee IS. Factors affecting the health-related quality of life among patients 
with chronic low back pain. Chungang University. Dissertation of Master's Degree. 2014.

2. Lee SC, Lee DT. Effects of exercise therapy on lower back pain patients. Asian J Kinesiol. 2007;9(2):69-78.

3. Kwon HR. The effects of lumbar self-exercise program on physical strength factors (strength, flexibility), pain and osi in patients with the chronic low back pain. Ewha womans University. Dissertation of Master' s Degree. 2005.

4. Shaikh M, Ostor AJ. Evaluating the paitent with low back pain. Practitoner. 2015;259(1788):21-4.

5. Choi MR. Pain reducing mechanism of horizontal vibration exercise in chronic low back pain patients. Dongguk University. Dissertation of Doctorate Degree. 2016.

6. Pillastrini P, Ferrari S, Rattin S et al. Exercise and tropism of the multifidus muscle in low back pain: a short review. J Phys Ther Sci, 2014;27(3): 943-5.

7. van Dieen JH, Selen LP, Cholewicki J. Trunk muscle activation in lowback pain patients, an analysis of the literature. J Electromyogr kinesiol. 2003;13(4):333-51.

8. MacDonald D, Moseley GL, Hodges PW. Why do some patients keep hurting their back? Evidence of ongoing back muscle dysfunction during remission from recurrent back pain. Pain. 2009;142(3):183-8.

9. Lee HO. Activation of trunk muscles during stabilization exercises in four-point kneeling. J Kor Soc Phys Ther. 2010;22(5):33-8.

10. Dionisio VC, Almeida GL, Duarte M et al. Kinematic, kinetic and EMG patterns during downward squatting. J Electromyogr Kinesiol. 2008; 18(1):134-43.

11. Park HS. Comparative analysis on muscle activities of lower limb depending on the types and load of squat exercise. Hanyang University. Dissertation of Master's Degree. 2016.

12. Witvrouw E, Danneels L, Van Tiggelen D et al. Open versus closed kinetic chain exercises in patellofemoral pain a 5-year prospective randomized study. Am J Sports Med. 2004;32(5):1122-30.

13. Boling MC, Bolgla LA, Mattacola CG et al. Outcomes of a weight-bearing rehabilitation program for patients diagnosed with patellofemoral pain syndrome. Arch Phys Med Rehabil. 2006;87(11):1428-35

14. Escamilla RF, Zheng N, Macleod TD et al. Patellofemoral joint force and stress during the wall squat and one-leg squat. Med Sci Sports Exerc. 2009;41(4):879-88.

15. Panjabi MM. The stabilizing system of the spine. part 1 . function dysfunction adaptation and enhancement. J Spinal Disord. 1992;5(4):383-9

16. Herrington L, Davies R. The influence of pilates training on the ability to contract the transversus abdominis muscle in asymptomatic individuals.
J Bodywork Mov Thera. 2005;9(1):52-7

17. Durall CJ, Udermann BE, Johansen DR et al. The effects of preseason trunk muscle training on low-back pain occurrence in women collegiate gymnasts. J Strength Cond Res. 2009;23(1):86-92.

18. Stuge B, Laerum E, Vollestad N et al. The efficacy of a treatment program focusing on specific stabilizing exercises for pelvic girdle pain after pregnancy: a randomized controlled trial. Spine. 2004;29(4):351-9.

19. Choi KE. The effects of core stability exercise on the balance and movement performance for dancing major students. Hanyang University. Dissertation of Master's Degree. 2011.

20. Cho IS. The effects of visual feedback balance training on pain, physical function, gait, balance in chronic knee osteoarthritis patients. Daegu University. Dissertation of Master's Degree. 2016.

21. Langhorne P, Coupar F, Pollock A. Motor recovery after stroke: a systematic review. Lancet Neurol. 2009;8(8):741-54.

22. Carey JR, Anderson KM, Kimberley TJ et al. FMRI analysis of ankle movement tracking training in subject with stroke. Exp Brain Res. 2004; 154(3):281-90.

23. Kim HY. The effects on gait and balance of the balance trainer controlled knee-joint mobility in subacute stroke patients. Daegu University. Dissertation of Master's Degree. 2014.

24. Jeong HJ, Kim YN, Cho WS et al. Effect of kettlebell swing exercise on the body composition and lower limb muscular activity. J Kor Phys Ther. 2017;29(4):194-200

25. Cho YM. The effects of unicycle exercise on core muscle thickness and balance. Nambu University. Dissertation of Master's Degree. 2018.

26. Lee SH, Kim TH, Lee BH. The effect of abdominal bracing in combination with low extremity movement on changes in abdominal muscles thickness and lumbar strength for low back pain. J Phys Ther Sci. 2014; 26(1):157-60

27. Do YC. A comparison of different type of surface during Plank exercise on transversus abdominis and internal obliques thickness using an ultrasound imaging. Inje University. Dissertation of Master's Degree. 2014

28. Lee TK. Abdominal muscles thickness changes during core endurance test in chronic low back pain patients. Kookmin University. Dissertation of Master's Degree. 2018.

29. Mun DJ. The effect of muscle stability excercise on muscle activity, muscle thickness and balance of core muscle. Seonam University. Dissertation of Doctorate Degree. 2016.

30. Nam DH. Effect of squats using visual feedback on the balance ability and thickness of quadriceps femoris and transversus abdominis muscle of college students in their 20s. Daegu University. Dissertation of Master' s Degree. 2017. 